\title{
Evaluación multivariante de la calidad del agua en la cuenca del Utcubamba (Perú)
}

\author{
Fernando Corroto ${ }^{1}$ \\ Oscar Gamarra ${ }^{2}$ \\ Elgar Barboza ${ }^{3}$
}

\footnotetext{
${ }^{1}$ Instituto de Investigación para el Desarrollo Sustentable de Ceja de Selva, Universidad Nacional Toribio Rodríguez de Mendoza, Perú, fernando.corroto@untrm.edu.pe

${ }^{2}$ Instituto de Investigación para el Desarrollo Sustentable de Ceja de Selva, Universidad Nacional Toribio Rodríguez de Mendoza, Perú, ogamarra@indes-ces.edu.pe

${ }^{3}$ Instituto de Investigación para el Desarrollo Sustentable de Ceja de Selva, Universidad Nacional Toribio Rodríguez de Mendoza, Perú, ebarboza@indes-ces.edu.pe
}

Autor para correspondencia: Fernando Corroto, fernando.corroto@untrm.edu.pe

\section{Resumen}

El aumento de la población a lo largo de la cuenca del río Utcubamba, sin la correspondiente implementación de sistemas de tratamiento de aguas residuales por parte de las autoridades, ha provocado la disminución en la calidad del agua, lo que constituye una amenaza para la salud pública y la preservación del ecosistema. El objetivo de este trabajo es disminuir el conjunto de datos recogidos en grandes cuencas hidrográficas tanto a nivel de estaciones de muestreo como a nivel de variables. Se realizaron muestreos en 43 estaciones situadas en el cauce principal y afluentes más importantes, y se analizó su calidad fisicoquímica y microbiológica a través de la determinación de 19 variables en tres campañas distintas (lluvias tempranas, lluvias y seca). Se aplicaron métodos estadísticos multivariantes (análisis de correlación, análisis de componentes principales y análisis cluster), para encontrar el origen de las fuentes de contaminación, naturales o antrópicas, y la distribución de la misma. Los resultados obtenidos muestran que los principales parámetros que afectan espacialmente la cuenca derivan de las altas concentraciones de bacterias y de 
compuestos químicos, como nitritos, fosfatos y amonio. Por último, el uso de metodologías multivariantes en el análisis de los resultados obtenidos permite disminuir el número tanto de variables como de estaciones de muestreo en futuras evaluaciones.

Palabras clave: calidad del agua, análisis de componentes principales, análisis cluster, río Utcubamba.

Recibido: $02 / 01 / 2017$

Aceptado: 15/03/2018

\section{Introducción}

Los Andes tropicales son, en el ámbito hidrológico, una de las regiones más diversas del planeta (Crespo et al., 2011). Por lo general, los ecosistemas fluviales altoandinos son importantes en sectores rurales y urbanos (Acosta, Ríos, Rieradevall, \& Prat, 2009), y es que sus cuencas hidrográficas aportan condiciones de vida favorables, derivadas de la función del agua como fuente de suministro en la agricultura, ganadería, industria y/o consumo humano. La calidad del agua en estos ecosistemas depende, principalmente, de diferentes factores antrópicos (Álvarez-Cabria, Barquín, \& Peñas, 2016), que modifican la variabilidad natural de los ríos, afectando sus características fisicoquímicas (Carrera \& Gunkel, 2003; Villamarín, Prat, \& Rieradevall, 2014), microbiológicas (Calizaya-Anco, AvendañoCáceres, \& Delgado-Vargas, 2013; Chamorro et al., 2013) e hidromorfológicas (Hamilton, Kellndorfer, Lehner, \& Tobler, 2007; Struth, Babault, \& Teixell, 2015).

Sin embargo, las perturbaciones sufridas en las cuencas altoandinas también tienen un origen natural, como el fuerte gradiente altitudinal que caracteriza a estas montañas (Jacobsen, 2004), que unido a la variación estacional en las precipitaciones, generan una degradación de suelos (Correa, Mello, Chou, Curi, \& Norton, 2016), que provoca que los ríos transporten una cantidad significativa de materia. Ambos orígenes, antrópico y natural, tienen fuertes efectos en la concentración de contaminantes en el agua (Vega, Pardo, Barrado, \& Debán, 1998).

Las variaciones estacionales en latitudes tropicales están muy acentuadas, marcadas sobre todo por el régimen de lluvias, por lo que 
la implementación de evaluaciones espacio-temporales a nivel de cuenca, y su relación con factores ambientales y humanos supone un aspecto básico en el diseño de medidas para el uso sostenible de los recursos hídricos en estas áreas (Velázquez-Machuca, PimentelEquihua, \& Ortega-Escobar, 2010). Para una interpretación correcta de los resultados obtenidos en programas de monitoreo espaciotemporales de cuencas hidrográficas, la aplicación de herramientas estadísticas multivariantes, como el análisis de componentes principales (ACP) y el análisis cluster (AC) resulta muy eficiente (Vieira et al., 2012). Estas metodologías para el análisis de datos se han aplicado en ecosistemas acuáticos diversos en los últimos años (p. ej., Picado et al., 2008; Olsen, Chappell, \& Loftis, 2012; Wang et al., 2013), con algunos estudios relacionados en Sudamérica (Dos Santos, De Oliveira, Bruns, \& Gennari, 2004; Villegas, Paredes, Betancur, \& Ribeiro, 2013).

Esta investigación se hizo a partir de los datos colectados en la cuenca del río Utcubamba (Perú), a lo largo de tres campañas diferentes de muestreo (2014-2015), con el propósito de reducir el amplio conjunto de datos que recogen las evaluaciones anuales en cuencas hidrográficas completas, y que en ocasiones son difíciles de interpretar y examinar. De esta manera, se evaluarán las correspondencias entre las variables fisicoquímicas y microbiológicas, además de las fuentes principales de contaminación y su distribución en la cuenca del río Utcubamba.

\section{Metodología}

\section{Descripción del área de estudio}

La cuenca del río Utcubamba, situada en el norte de Perú, en el Departamento Amazonas (Figura 1), está localizada entre los $5^{\circ} 32^{\prime}$ $36^{\prime \prime}$ y 6 50' 49" latitud sur; y 72॰ 22' 49" y 78 29' 59"' longitud oeste. El cauce principal tiene una extensión de unos $250 \mathrm{~km}$ y ocupa un área de $6650.07 \mathrm{~km}^{2}$. La naciente se ubica en el cerro Punta de Arena (provincia de Chachapoyas) a $4130 \mathrm{msnm}$ y desemboca en el río Marañón (provincia de Bagua) a 360 msnm. 


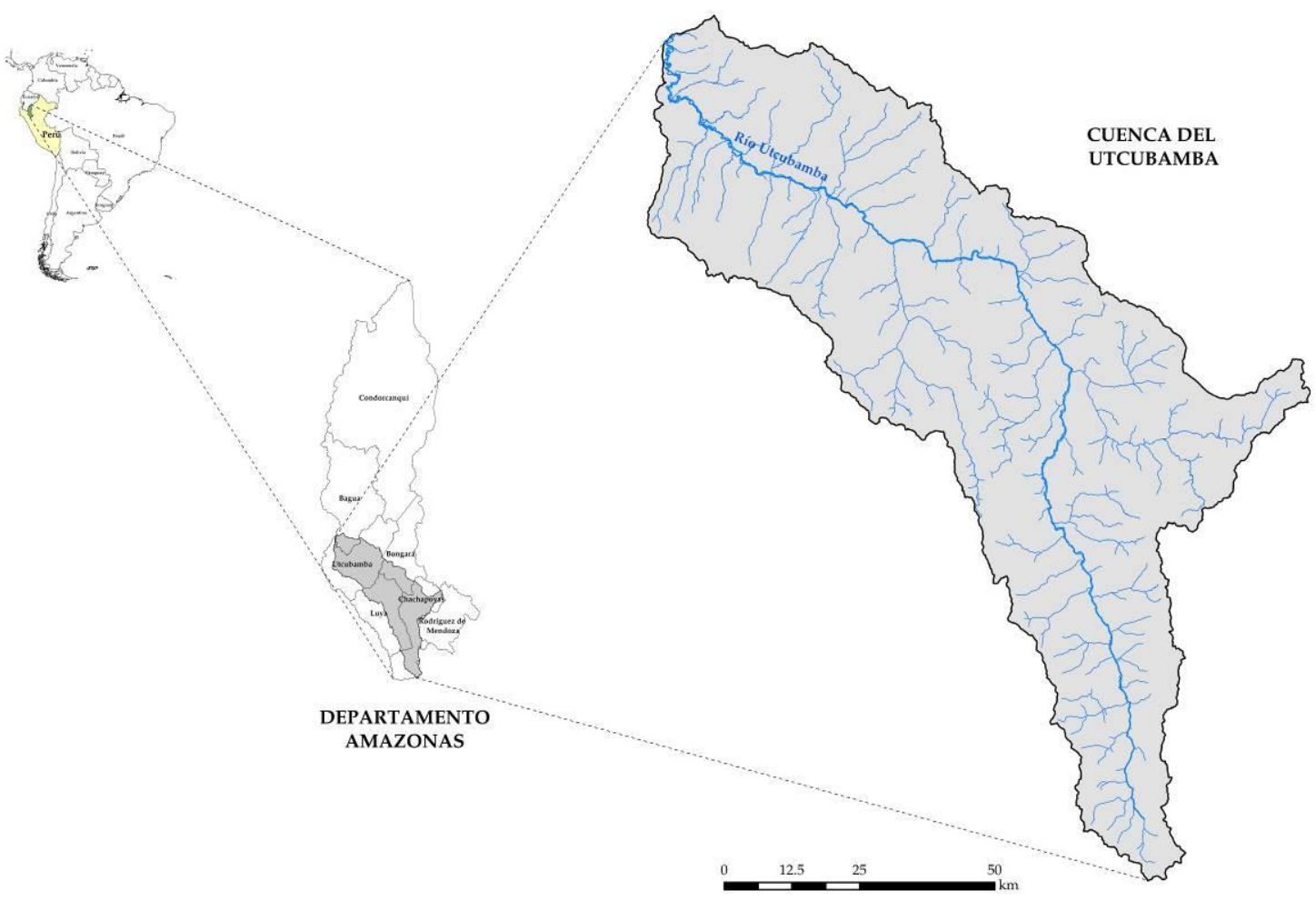

Figura 1. Área de estudio en la cuenca del río Utcubamba, Amazonas, Perú.

Las cuencas media y baja se encuentran englobadas dentro de los ecosistemas de bosques tropicales estacionalmente secos, que comprenden los valles de los ríos Marañón, Chamaya, Chinchipe y el propio Utcubamba (Linares-Palomino, 2004), mientras que la cuenca alta corresponde con los bosques pluviales montanos, situados en la franja alta de la vertiente oriental y la faja entre los ríos Huancabamba y Chinchipe (León, Pitman, \& Roque, 2006).

La cuenca del Utcubamba concentra un total de 220048 habitantes. Sus principales núcleos urbanos son las ciudades de Leymebamba, Chachapoyas, Pedro Ruíz Gallo, Bagua Grande, Cajaruro, El Milagro y Bagua (INEI, 2009), y las principales cargas contaminantes en la cuenca derivan de las propias aguas residuales domésticas de estos grandes centros, además de la ganadería y escorrentía agrícola.

\section{Selección de las estaciones de muestreo}


Se seleccionaron 43 estaciones de muestreo (Figura 2), adaptando y siguiendo la metodología marcada por Freshwater Ecology and Management para la evaluación del estado ecológico de los ríos Mediterráneos (Prat, Rieradevall, \& Fortuño, 2012). Los principales tributarios considerados fueron los siguientes: San Miguel (EM-2); El Chorro (EM-4); Pauca (EM-6); Singache (EM-9); Cedrocucho (EM-11); Yuyac (EM-13); Rumiyacu (EM-15); Tosán (EM-17); Sonche (EM-20); Cocahuayco (EM-22); El Chido (EM-24); Tingo (EM-27); Magunchal (EM-30); Naranjos (EM-32); Honda (EM-33); Goncha (EM-37); San Juan (EM-40), y La Peca (EM-41). 


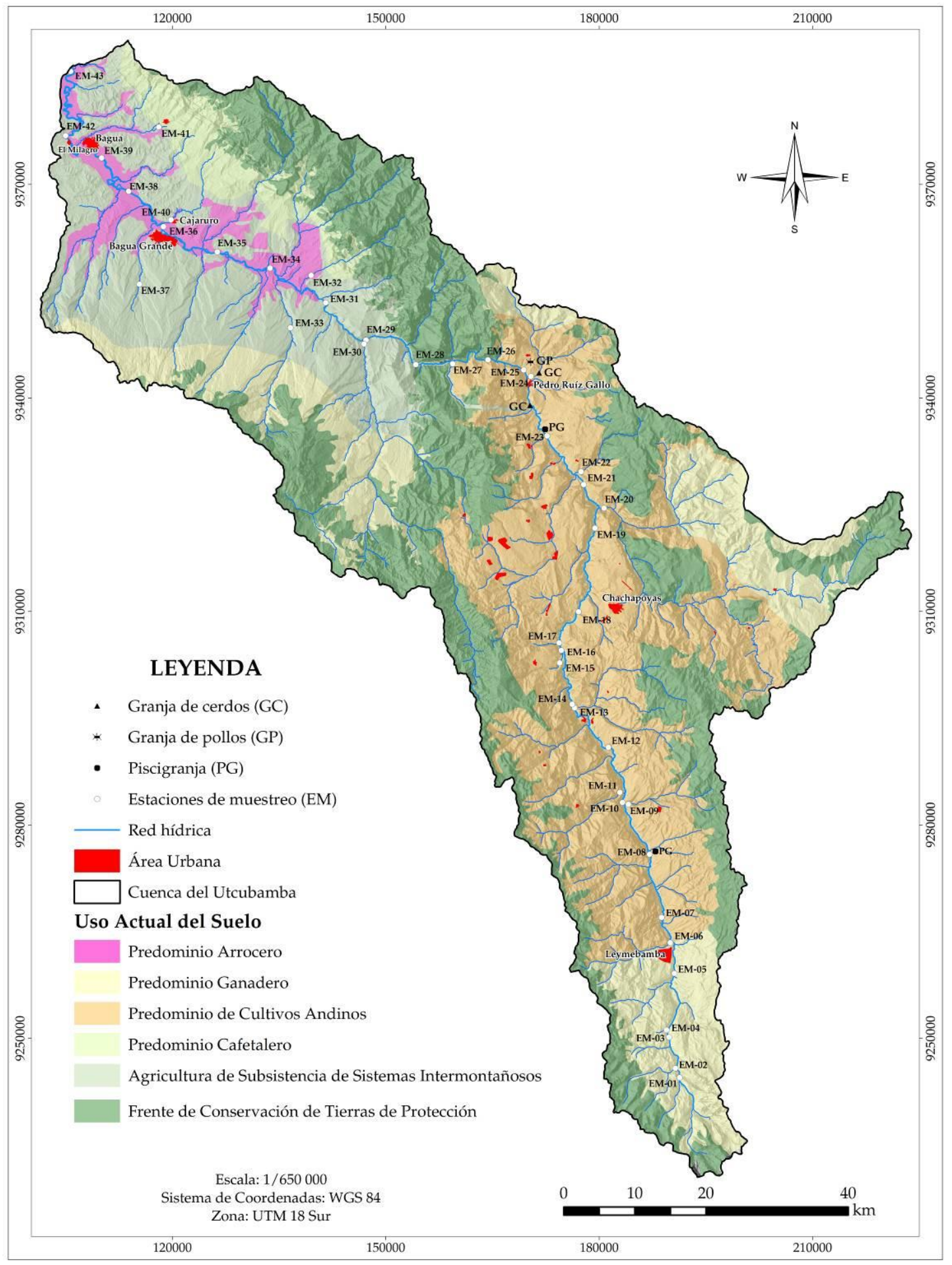

Figura 2. Estaciones de muestreo (EM) en la cuenca del río Utcubamba, Amazonas, Perú.

\section{Muestreo y recolección de datos}


La recolección de muestras de agua se realizó entre los años 2014 y 2015, a lo largo de tres campañas de muestreo que se hicieron coincidir con la temporada de lluvias tempranas (durante octubre de 2014), la temporada de lluvias (marzo de 2015) y la estación seca (agosto de 2015).

Para la recolección de muestras se siguió el protocolo de monitoreo de la calidad sanitaria de los recursos hídricos superficiales, establecido por la Dirección General de Salud Ambiental del Perú (Digesa, 2007), mientras que para el análisis de las variables fisicoquímicas y microbiológicas se hizo lo propio con los procedimientos de la American Public Health Association (Greenberg, Clesceri, \& Eaton. (1992).

Los parámetros estudiados se establecieron en función de las actividades contaminantes en la cuenca y fueron 19 en total: oxígeno disuelto (OD); conductividad eléctrica (CE); temperatura $(\mathrm{T})$; $\mathrm{pH}$; turbiedad (TURB); nitratos (NITRA); nitritos (NITRI); fosfatos (FOSFA); sulfatos (SULFA); amonio (AMO); demanda química de oxígeno (DQO); demanda bioquímica de oxígeno en cinco días (DBO); alcalinidad (ALCA); cloruros (CLO); dureza (DUR); coliformes totales (CT); coliformes fecales (CF); Escherichia coli (EC), y enterococos fecales (EF).

\section{Análisis estadísticos}

Los datos obtenidos se ingresaron en una hoja de cálculo de Microsoft Excel; se analizaron con el software Past 3.0 (Hammer, Harper, \& Ryan, 2001).

En esencia, se emplearon dos metodologías estadísticas: análisis de componentes principales (ACP) y análisis cluster (AC). El ACP es utilizado para sintetizar la información entre las variables establecidas y eliminar la colinealidad entre ellas, creando nuevas variables (componentes principales $\mathrm{CP}$ ) que no están correlacionadas. De esta manera, el primer componente principal (PC 1) manifiesta la mayor proporción de varianza explicada (Terradez, 2002). Por otra parte, el AC es una técnica que utiliza la información de una serie de variables en función de un objeto, para dividir los datos en clases basadas en su similitud. Una vez medida la similitud, se agrupan en grupos 
homogéneos internamente y diferentes entre sí. En el AC se usó como distancia de medida, así como la distancia euclídea; el método de agrupación empleado fue el de Ward, a través del cual se pueden concentrar las variables o las estaciones de muestreo de forma jerárquica, de tal manera que se minimice una determinada función y los dos objetos con la distancia más baja se unan para formar un nuevo grupo (Hair, Anderson, Tatham, \& Black, 1999). El principal objetivo del Método Ward es el de unir, en cada paso del proceso de aglomeración, las dos clases que incrementen menos la inercia intraclases (Pardo \& Del Campo, 2007).

En conclusión, las razones por las cuales se utilizaron estas dos pruebas estadísticas son las marcadas por Vieira et al. (2012), y se resumen a continuación: 1) agrupar las estaciones de muestreo en función de la calidad del agua, con el objetivo de optimizar el número de estaciones de muestreo y, por lo tanto, en futuras evaluaciones reducir el número de muestreos; 2) identificar las variables correlacionadas, con la finalidad de reducir el número de las mismas a analizar por muestra, y en consecuencia, reducir costos en futuros monitoreos.

Por último, las diferencias significativas existentes entre las concentraciones de las variables analizadas se evaluaron con la ayuda de matrices de correlación entre las tres diferentes campañas de muestreo. El coeficiente de correlación establecido fue significativo por debajo de $0.01(p<0.01)$.

\section{Resultados y discusión}

\section{Correlación de variables y fuentes de contaminación}

Para establecer la correlación existente entre las variables seleccionadas para este estudio se elaboró una matriz de correlación (Tabla 1), en la cual los coeficientes de correlación estadísticamente significativos (con un nivel de significación de 0.01) están marcados en negrita. Se dieron altas correlaciones entre todas las variables microbiológicas (CT y CF; CT y EC; CT y EF; CF y EC; CF y EF, y EC y EF). La Agencia de Protección Medioambiental recomienda el empleo de Escherichia coli y miembros del género Enterococcus, como 
indicadores de contaminación fecal en las aguas superficiales (USEPA, 2000). La aparición en grandes concentraciones de Escherichia coli, que habita en el intestino de los animales homeotermos (Sunantha \& Vasudevan, 2016), y teniendo en cuenta que su capacidad de reproducción fuera del intestino de estos animales está favorecida por la existencia de condiciones adecuadas de materia orgánica y $\mathrm{pH}$ (Prescott, Harley, \& Klein, 1996; Arcos-Pulido, Ávila-de-Navia, Estupiñán-Torres, \& Gómez-Prieto, 2005) genera un escenario que se cumple en gran parte de la cuenca del río Utcubamba.

Tabla 1. Matriz de correlación de la calidad del agua en el río Utcubamba. Valores en negrita corresponden a coeficientes de correlación estadísticamente significativos $(p<0.01)$.

\begin{tabular}{|c|c|c|c|c|c|c|c|c|c|c|c|c|c|c|c|c|c|c|c|}
\hline & OD & CE & $\mathbf{T}$ & pH & $\begin{array}{l}\text { TU } \\
\text { RB }\end{array}$ & $\begin{array}{l}\text { NI } \\
\text { TR } \\
\text { A }\end{array}$ & \begin{tabular}{|c} 
NIT \\
RO
\end{tabular} & $\begin{array}{l}\text { FO } \\
\text { SF } \\
\text { A }\end{array}$ & \begin{tabular}{|c} 
SUL \\
FA
\end{tabular} & $\begin{array}{c}\text { AM } \\
0\end{array}$ & $\begin{array}{c}\mathrm{DQ} \\
\mathrm{O}\end{array}$ & $\begin{array}{c}\text { DB } \\
0\end{array}$ & $\begin{array}{c}\text { ALC } \\
\text { A }\end{array}$ & $\begin{array}{l}\mathrm{CL} \\
\mathbf{0}\end{array}$ & $\begin{array}{c}\text { DU } \\
\text { R }\end{array}$ & CT & CF & EC & $\begin{array}{l}\mathbf{E} \\
\mathbf{F}\end{array}$ \\
\hline OD & 1 & & & & & & & & & & & & & & & & & & \\
\hline CE & $\begin{array}{l}- \\
0.3 \\
13\end{array}$ & 1 & & & & & & & & & & & & & & & & & \\
\hline $\mathrm{T}$ & $\begin{array}{l}-\overline{0} \\
75\end{array}$ & $\begin{array}{l}0.6 \\
01\end{array}$ & 1 & & & & & & & & & & & & & & & & \\
\hline $\mathrm{pH}$ & $\begin{array}{l}0.2 \\
24\end{array}$ & $\begin{array}{l}0.2 \\
79\end{array}$ & $\begin{array}{c}0.1 \\
15\end{array}$ & 1 & & & & & & & & & & & & & & & \\
\hline $\begin{array}{l}\text { TU } \\
\text { RB }\end{array}$ & $\begin{array}{l}-\overline{0} \\
0.1 \\
56\end{array}$ & $\begin{array}{l}0.5 \\
24\end{array}$ & $\begin{array}{l}0.7 \\
13\end{array}$ & $\begin{array}{l}0.0 \\
13\end{array}$ & 1 & & & & & & & & & & & & & & \\
\hline $\begin{array}{l}\text { NIT } \\
\text { RA }\end{array}$ & $\begin{array}{l}-\overline{0} \\
0.1 \\
39\end{array}$ & $\begin{array}{l}0.6 \\
75\end{array}$ & $\begin{array}{c}0.6 \\
61\end{array}$ & $\begin{array}{l}0.1 \\
47\end{array}$ & $\begin{array}{l}0.5 \\
95\end{array}$ & 1 & & & & & & & & & & & & & \\
\hline $\begin{array}{l}\text { NIT } \\
\text { RO }\end{array}$ & $\begin{array}{l}0.3 \\
57\end{array}$ & $\begin{array}{l}0.1 \\
70\end{array}$ & $\begin{array}{l}0.3 \\
18\end{array}$ & $\begin{array}{l}0.1 \\
49\end{array}$ & $\begin{array}{l}0.3 \\
54\end{array}$ & $\begin{array}{l}0.5 \\
21\end{array}$ & 1 & & & & & & & & & & & & \\
\hline $\begin{array}{l}\text { FO } \\
\text { SF } \\
\text { A }\end{array}$ & $\begin{array}{l}0.3 \\
17\end{array}$ & $\begin{array}{l}0.6 \\
74\end{array}$ & $\begin{array}{l}0.6 \\
15\end{array}$ & $\begin{array}{l}0.0 \\
35\end{array}$ & $\begin{array}{l}0.5 \\
74\end{array}$ & $\begin{array}{c}0.6 \\
82\end{array}$ & \begin{tabular}{|l|}
0.4 \\
23
\end{tabular} & 1 & & & & & & & & & & & \\
\hline $\begin{array}{l}\text { SU } \\
\text { LFA }\end{array}$ & $\begin{array}{l}- \\
0.1 \\
69\end{array}$ & $\begin{array}{c}0.8 \\
53\end{array}$ & $\begin{array}{l}0.5 \\
67\end{array}$ & $\begin{array}{l}0.2 \\
67\end{array}$ & $\begin{array}{l}0.3 \\
44\end{array}$ & $\begin{array}{l}0.6 \\
10\end{array}$ & $\begin{array}{c}0.2 \\
52\end{array}$ & $\begin{array}{l}0.6 \\
35\end{array}$ & 1 & & & & & & & & & & \\
\hline $\begin{array}{l}\text { AM } \\
\text { O }\end{array}$ & $\begin{array}{l}0.1 \\
63\end{array}$ & $\begin{array}{l}0.5 \\
66\end{array}$ & $\begin{array}{l}0.2 \\
90\end{array}$ & $\begin{array}{l}0.1 \\
33\end{array}$ & $\begin{array}{l}0.3 \\
24\end{array}$ & $\begin{array}{l}0.5 \\
00\end{array}$ & \begin{tabular}{|c|}
0.4 \\
99
\end{tabular} & \begin{tabular}{|l|}
0.6 \\
18
\end{tabular} & $\begin{array}{l}0.4 \\
68\end{array}$ & 1 & & & & & & & & & \\
\hline $\begin{array}{l}\text { DQ } \\
\text { O }\end{array}$ & $\begin{array}{l}- \\
0.2 \\
00\end{array}$ & $\begin{array}{l}0.0 \\
14\end{array}$ & $\begin{array}{l}- \\
0.0 \\
39\end{array}$ & $\begin{array}{l}- \\
0.0 \\
56\end{array}$ & $\begin{array}{l}0.1 \\
46\end{array}$ & $\begin{array}{l}0.1 \\
48\end{array}$ & \begin{tabular}{|c|}
0.2 \\
00
\end{tabular} & \begin{tabular}{|l|}
0.1 \\
28
\end{tabular} & $\begin{array}{l}\overline{0.1} \\
81\end{array}$ & $\begin{array}{l}0.1 \\
06\end{array}$ & 1 & & & & & & & & \\
\hline $\begin{array}{l}\text { DB } \\
\text { O }\end{array}$ & $\begin{array}{l}0.0 \\
20\end{array}$ & $\begin{array}{c}0.5 \\
93\end{array}$ & $\begin{array}{l}0.4 \\
68\end{array}$ & $\begin{array}{l}0.1 \\
88\end{array}$ & $\begin{array}{l}0.4 \\
88\end{array}$ & \begin{tabular}{|l|}
0.5 \\
74
\end{tabular} & \begin{tabular}{|c|}
0.3 \\
91
\end{tabular} & \begin{tabular}{|l|}
0.5 \\
13
\end{tabular} & $\begin{array}{l}0.3 \\
75\end{array}$ & $\begin{array}{l}0.5 \\
29\end{array}$ & $\begin{array}{l}0.3 \\
92\end{array}$ & 1 & & & & & & & \\
\hline $\begin{array}{l}\mathrm{AL} \\
\mathrm{CA}\end{array}$ & $\begin{array}{c}- \\
0.4 \\
53\end{array}$ & $\begin{array}{c}0.6 \\
35\end{array}$ & $\begin{array}{l}0.2 \\
09\end{array}$ & $\begin{array}{l}0.3 \\
80\end{array}$ & $\begin{array}{l}0.2 \\
19\end{array}$ & $\begin{array}{l}0.3 \\
98\end{array}$ & $\begin{array}{l}0.0 \\
25\end{array}$ & \begin{tabular}{|l|}
0.3 \\
43
\end{tabular} & $\begin{array}{c}0.6 \\
08\end{array}$ & $\begin{array}{l}0.1 \\
02\end{array}$ & $\begin{array}{l}0.0 \\
94\end{array}$ & $\begin{array}{l}0.3 \\
07\end{array}$ & 1 & & & & & & \\
\hline $\begin{array}{l}\mathrm{CL} \\
\mathrm{O}\end{array}$ & $\begin{array}{l}0.0 \\
01\end{array}$ & $\begin{array}{c}0.6 \\
09\end{array}$ & $\begin{array}{l}0.1 \\
65\end{array}$ & $\begin{array}{l}0.0 \\
69\end{array}$ & $\begin{array}{l}0.2 \\
92\end{array}$ & $\begin{array}{l}0.3 \\
82\end{array}$ & $\begin{array}{l}0.2 \\
03\end{array}$ & \begin{tabular}{|l|}
0.3 \\
89
\end{tabular} & $\begin{array}{c}0.4 \\
49\end{array}$ & $\begin{array}{l}0.6 \\
99\end{array}$ & $\begin{array}{l}0.2 \\
23\end{array}$ & $\begin{array}{l}0.4 \\
52\end{array}$ & $\begin{array}{l}0.1 \\
31\end{array}$ & 1 & & & & & \\
\hline
\end{tabular}




\begin{tabular}{|c|c|c|c|c|c|c|c|c|c|c|c|c|c|c|c|c|c|c|c|}
\hline $\begin{array}{l}\text { DU } \\
\text { R }\end{array}$ & $\begin{array}{c}- \\
0.2 \\
38\end{array}$ & $\begin{array}{l}0.8 \\
29\end{array}$ & $\begin{array}{l}0.5 \\
34\end{array}$ & $\begin{array}{l}0.4 \\
81\end{array}$ & $\begin{array}{l}0.2 \\
95\end{array}$ & $\begin{array}{c}0.5 \\
48\end{array}$ & $\begin{array}{l}0.1 \\
27\end{array}$ & $\begin{array}{l}0.5 \\
05\end{array}$ & $\begin{array}{c}0.8 \\
68\end{array}$ & $\begin{array}{l}0.3 \\
00\end{array}$ & $\begin{array}{l}- \\
0.0 \\
49\end{array}$ & $\begin{array}{l}0.4 \\
27\end{array}$ & $\begin{array}{l}0.7 \\
77\end{array}$ & $\begin{array}{l}0.3 \\
59\end{array}$ & 1 & & & & \\
\hline CT & $\begin{array}{l}0.3 \\
27\end{array}$ & $\begin{array}{c}0.4 \\
48\end{array}$ & $\begin{array}{l}0.4 \\
77\end{array}$ & $\begin{array}{l}0.3 \\
25\end{array}$ & $\begin{array}{l}0.3 \\
12\end{array}$ & $\begin{array}{c}0.5 \\
04\end{array}$ & $\begin{array}{c}0.4 \\
43\end{array}$ & $\begin{array}{l}0.3 \\
61\end{array}$ & $\begin{array}{l}0.5 \\
36\end{array}$ & $\begin{array}{c}0.4 \\
43\end{array}$ & $\begin{array}{l}0.3 \\
25\end{array}$ & $\begin{array}{l}0.3 \\
48\end{array}$ & $\begin{array}{c}0.1 \\
92\end{array}$ & $\begin{array}{l}0.2 \\
41\end{array}$ & $\begin{array}{c}0.4 \\
82\end{array}$ & 1 & & & \\
\hline CF & $\begin{array}{l}0.4 \\
21\end{array}$ & $\begin{array}{l}0.3 \\
78\end{array}$ & $\begin{array}{l}0.3 \\
70\end{array}$ & $\begin{array}{l}0.2 \\
62\end{array}$ & $\begin{array}{l}0.3 \\
23\end{array}$ & $\begin{array}{l}0.4 \\
37\end{array}$ & $\begin{array}{c}0.4 \\
65\end{array}$ & $\begin{array}{l}0.3 \\
33\end{array}$ & $\begin{array}{l}0.4 \\
94\end{array}$ & $\begin{array}{l}0.4 \\
55\end{array}$ & $\begin{array}{c}- \\
0.4 \\
02\end{array}$ & $\begin{array}{c}0.2 \\
94\end{array}$ & $\begin{array}{l}0.0 \\
69\end{array}$ & $\begin{array}{l}0.2 \\
89\end{array}$ & $\begin{array}{l}0.3 \\
77\end{array}$ & $\begin{array}{l}0.9 \\
13\end{array}$ & 1 & & \\
\hline EC & $\begin{array}{l}0.3 \\
62\end{array}$ & $\begin{array}{l}0.1 \\
77\end{array}$ & $\begin{array}{l}0.0 \\
41\end{array}$ & $\begin{array}{l}0.2 \\
06\end{array}$ & $\begin{array}{c}0.0 \\
99\end{array}$ & $\begin{array}{l}0.0 \\
89\end{array}$ & $\begin{array}{l}0.3 \\
67\end{array}$ & $\begin{array}{l}0.0 \\
78\end{array}$ & $\begin{array}{c}0.2 \\
19\end{array}$ & $\begin{array}{l}0.4 \\
01\end{array}$ & $\begin{array}{c}0.2 \\
52\end{array}$ & $\begin{array}{l}0.1 \\
37\end{array}$ & $\begin{array}{c}- \\
0.0 \\
54\end{array}$ & $\begin{array}{c}0.3 \\
19\end{array}$ & $\begin{array}{c}0.1 \\
50\end{array}$ & $\begin{array}{l}0.5 \\
45\end{array}$ & $\begin{array}{c}0.6 \\
56\end{array}$ & 1 & \\
\hline EF & $\begin{array}{l}0.3 \\
08\end{array}$ & $\begin{array}{c}0.5 \\
19\end{array}$ & $\begin{array}{l}0.4 \\
17\end{array}$ & $\begin{array}{l}0.1 \\
66\end{array}$ & $\begin{array}{c}0.4 \\
63\end{array}$ & $\begin{array}{c}0.5 \\
26\end{array}$ & $\begin{array}{c}0.4 \\
90\end{array}$ & $\begin{array}{c}0.4 \\
61\end{array}$ & $\begin{array}{l}0.5 \\
27\end{array}$ & $\begin{array}{l}0.7 \\
78\end{array}$ & $\begin{array}{l}0.0 \\
27\end{array}$ & $\begin{array}{c}0.4 \\
30\end{array}$ & $\begin{array}{l}0.0 \\
78\end{array}$ & $\begin{array}{l}0.6 \\
17\end{array}$ & $\begin{array}{l}0.3 \\
30\end{array}$ & $\begin{array}{c}0.6 \\
11\end{array}$ & $\begin{array}{c}0.6 \\
15\end{array}$ & $\begin{array}{c}0.4 \\
84\end{array}$ & 1 \\
\hline
\end{tabular}

En este sentido, las altas correlaciones entre parámetros fisicoquímicos y microbiológicos están asociadas con la contaminación antrópica (Vieira et al., 2012), derivada tanto de descargas residuales domésticas como de aguas residuales de ganado. Esto se vio reflejado en que la DQO y DBO, correlacionadas entre sí, manifestaron de igual manera altas correlaciones con CF, cuyo origen puede ser animal $\mathrm{o}$ humano. No existen plantas de tratamiento de aguas residuales en ninguna localidad de la región, y cabe señalar que la capital y ciudad más poblada de la misma, Chachapoyas, que no está situada en el Valle del Utcubamba, vierte sus aguas negras al río, a través de la Quebrada Santa Lucía y el río Sonche, tributarios del Utcubamba, aumentando la concentración en los niveles bacteriológicos y fisicoquímicos en el agua de la cuenca receptora (Chávez, Leiva, \& Corroto, 2016).

Asimismo, las altas correlaciones que se dieron entre DBO, DQO, nitratos, fosfatos, nitritos y conductividad eléctrica certificaron fuentes de contaminación similares a las anteriores, es decir, de origen fecal; sin embargo, al evaluar las actividades que se desempeñan a lo largo de la cuenca, se evidenciaron algunas diferencias. Así, en los tramos alto y medio, entre la estación de muestreo 1 (2 $834 \mathrm{msnm}$ ) y la 26 (1 $088 \mathrm{msnm}$ ), la fuente de contaminación que derivó en estas altas correlaciones de los elementos citados resultó del vertimiento de aguas residuales procedentes de los principales centros poblados (Leymebamba, Chachapoyas y Pedro Ruíz), y del ganado vacuno disperso en el área. La oxidación de residuos nitrogenados de origen humano y las excretas de animales, al igual que efluentes industriales aportan para este escenario (Chidya, Sajidu, Mwatseteza, \& Masamba, 2011). Cabe destacar la presencia extraordinaria de dos piscifactorías de trucha arcoíris (Oncorhynchus mykiss) en estos dos tramos de la cuenca. Si bien los criaderos son locales y no ofrecen mucha producción, la descarga de sus efluentes en el río Utcubamba pudo verse reflejado en la concentración de nitratos y fosfatos, y es que 
según Schulz, Gelbrecht y Rennert (2003), el remanente estándar producido en estiércol de criaderos de truchas está compuesto de 7 a $32 \%$ de nitrógeno total, y de 30 a $84 \%$ de fósforo total. Otro aspecto singular en la cuenca del río fue la presencia de dos granjas de cerdos en el tramo medio. La mayor parte de las aguas residuales de la industria porcina son ricas en compuestos de nitrógeno y fósforo (e.g., Martínez-García et al., 2009; Xu, Zhao, Zhao, \& Zhang, 2015), hecho que también contribuyó en las correlaciones antes citadas. En esta línea, la existencia de una granja de pollos en este tramo medio también sumó en la presencia en el río de los compuestos descritos, en especial del AMO, el cual aumenta con el incremento de stock en granjas avícolas (Rossignol, Paerl, Fear, \& Braddy, 2011).

En contraste, las correlaciones existentes entre las variables fisicoquímicas antes mencionadas en el tramo bajo, entre las estaciones de muestreo 27 (880 msnm) y 43 (386 msnm), se correspondió con el desarrollo agrícola. El valle seco de Bagua ha tenido interés agrícola en los últimos 25 años, sobre todo para la siembra de arroz en pozas; en consecuencia, una gran porcentaje del valle ha sido deforestado para este fin. En las provincias de Bagua y Utcubamba, este cultivo tiene una producción anual que bordea las 250000 toneladas métricas, convirtiéndose en el cultivo agrícola más importante en volumen y valor de producción en la región (Perú-IIAP, 2008). La distribución estacional de NITRA, FOSFA, CLO y AMO en el tramo bajo del río Utcubamba está vinculada con la aplicación de fertilizantes químicos en las zonas agrícolas del área de drenaje, siendo el fosfato diamónico (DAP), la urea y el cloruro de amonio los más usados en la región. Los nitratos no son bien retenidos por los suelos y al no ser utilizados con rapidez por las plantas se pierden por el drenaje (Martínez-García et al., 2009; Arias, Pérez, \& Rueda, 2004). El DAP es una fuente de nitrógeno (18\%) y fosfato $(20 \%)$ (Tanaka, Diagne, \& Saito, 2015) utilizado en el cultivo de arroz (Wopereis-Pura, Watanabe, Moreira, \& Wopereis, 2002; Solaraj, Dhanakumar, Murthy, \& Mohanraj, 2010; Zhang, Gao, Fan, Lan, \& Zhao, 2017), y considerado como el fertilizante de fosfato más utilizado (Azizullah, Nasir, Richter, Lebert, \& Häder, 2011). La urea contiene un 46\% de nitrógeno (Zou, Lu, Li, \& Li 2011), y se emplea de forma complementaria con el DAP, provocando a través de su drenaje en suelos y su desagüe de manera directa las altas concentraciones reflejadas en el agua del Utcubamba en cuanto a estos tres parámetros químicos. A la gran carga bacteriana que llega a este tramo de la cuenca hay que añadir la aportada, de nuevo, por el vertido de aguas domésticas sin tratar de las ciudades de Bagua Grande y Bagua, las más pobladas del tramo en cuestión.

Finalmente, la alta correlación que existió entre la DUR y la ALCA es común en diversos estudios (p. ej., Segnini \& Chacón, 2005; Chidya et 
al., 2011) y deriva de la geología del área de estudio, compuesto de manera principal por calcitas y dolomitas, que confieren al $\mathrm{pH}$ del suelo un carácter básico.

\section{ACP de las variables establecidas}

Tanto para la selección del número de componentes principales (CP) como para la clasificación de la influencia de las variables en cada CP, se adaptó la línea marcada por Vieira et al. (2012) en su investigación en el río Lis (Portugal). Así, en cuanto a la selección del número de $\mathrm{CP}$, se escogieron los valores propios mayores de 1 (Kaiser, 1958), por lo que se seleccionaron los primeros cinco $\mathrm{CP}$, que representaron $80.50 \%$ con respecto a la varianza original. Los valores correspondientes a cada uno de estos cinco CP se clasificaron con base en la influencia de las variables en cada uno de los mismos, resultando los valores $\geq 0.3$ los que más contribuyeron (Tabla 2). De esta manera, 13 variables fueron las que más contribuyeron a partir de las 19 iniciales. Estos datos son análogos a los obtenidos por Singh, Malik, Mohan y Sinha (2004) en su estudio del río Gomti con técnicas estadísticas multivariantes, donde tras el ACP vio reducidas sus variables de 24 a 14 , explicando un $71 \%$ de la varianza total del conjunto de datos.

Tabla 2. Valores obtenidos y valores propios del ACP para las variables de calidad del agua. Los valores en negrita corresponden a las variables que contribuyen de forma significativa en cada CP.

\begin{tabular}{|l|c|c|c|c|c|}
\hline & CP 1 & CP 2 & CP 3 & CP 4 & CP 5 \\
\hline OD & -0.003 & $\mathbf{0 . 4 8 8}$ & 0.026 & 0.051 & 0.264 \\
\hline CE & $\mathbf{0 . 3 1 1}$ & -0.202 & -0.100 & 0.107 & -0.159 \\
\hline T & 0.250 & -0.096 & 0.021 & $\mathbf{- 0 . 4 5 7}$ & 0.086 \\
\hline PH & 0.116 & 0.056 & $\mathbf{- 0 . 3 2 6}$ & $\mathbf{0 . 3 1 0}$ & $\mathbf{0 . 5 2 5}$ \\
\hline TURB & 0.226 & -0.099 & 0.216 & $\mathbf{- 0 . 3 7 2}$ & 0.032 \\
\hline NITRA & 0.290 & -0.103 & 0.108 & -0.184 & 0.124 \\
\hline NITRO & 0.191 & 0.211 & 0.252 & -0.084 & $\mathbf{0 . 3 6 9}$ \\
\hline FOSFA & 0.273 & -0.160 & 0.149 & -0.160 & -0.119 \\
\hline SULFA & $\mathbf{0 . 3 0 0}$ & -0.114 & -0.242 & 0.028 & -0.164 \\
\hline AMO & 0.260 & 0.132 & 0.242 & 0.257 & -0.200 \\
\hline DQO & 0.007 & -0.224 & $\mathbf{0 . 4 6 7}$ & 0.289 & $\mathbf{0 . 3 5 7}$ \\
\hline
\end{tabular}




\begin{tabular}{|l|c|c|c|c|c|}
\hline DBO & 0.242 & -0.086 & 0.238 & 0.113 & 0.249 \\
\hline ALCA & 0.172 & $\mathbf{- 0 . 3 2 8}$ & $\mathbf{- 0 . 3 0 2}$ & 0.188 & 0.173 \\
\hline CLO & 0.215 & 0.017 & 0.210 & $\mathbf{0 . 4 3 0}$ & $\mathbf{- 0 . 3 4 9}$ \\
\hline DUR & 0.269 & -0.200 & $\mathbf{- 0 . 3 3 1}$ & 0.123 & 0.075 \\
\hline CT & 0.257 & 0.271 & -0.201 & -0.148 & 0.058 \\
\hline CF & 0.241 & $\mathbf{0 . 3 4 6}$ & -0.170 & -0.138 & -0.035 \\
\hline EC & 0.142 & $\mathbf{0 . 3 7 7}$ & -0.088 & 0.159 & -0.131 \\
\hline EF & 0.272 & 0.216 & 0.157 & 0.104 & -0.142 \\
\hline $\begin{array}{l}\text { Valores } \\
\text { propios }\end{array}$ & 7.732 & 2.964 & 2.041 & 1.392 & 1.165 \\
\hline
\end{tabular}

En el CP 2, las variables que más influyeron (CF, EC y OD) estuvieron asociadas con la contaminación fecal que se da a lo largo de toda la cuenca. Las dos primeras - CF y EC- están relacionadas de manera directa con los desechos fecales tanto humanos como animales (Gemmell \& Schmidt, 2012), y el OD puede estar ligado con condiciones fisicoquímicas cambiantes provocadas por bacterias indicadoras de contaminación fecal suspendidas en el agua (Tshibanda et al., 2014). Por el contrario, en el CP 3, la presencia de $\mathrm{pH}$, DUR y ALCA, como variables con mayor contribución, estuvo asociada con las características químicas del agua procedentes de las propiedades químicas del suelo calcáreo existente en la cuenca. EI CP 5 estuvo moderadamente influenciado por el $\mathrm{pH}$, NITRO, DQO y CLO. Este grupo de variables asociadas es similar al encontrado por Arpajón et al. (2011) en su estudio realizado en el río Almendrares (Cuba), donde la presencia en grandes concentraciones de nitritos en el agua mostró una contaminación orgánica de origen fecal procedente de áreas pobladas.

La contribución de la TURB en el CP 4 tiene su origen en la estacionalidad propia de la región, con una época lluviosa que influye directamente en esta característica física del agua. Asimismo, volvieron a aparecer variables como $\mathrm{pH}$ y CLO, que podrían tener su raíz en la contaminación fecal, sin embargo su presencia junto con la TURB impide encontrar un origen común.

\section{AC de las variables establecidas}


El AC permitió reunir de igual manera a grupos de variables en función de su similitud (Figura 3). Los grupos formados (GF) fueron, a grandes rasgos, los siguientes:

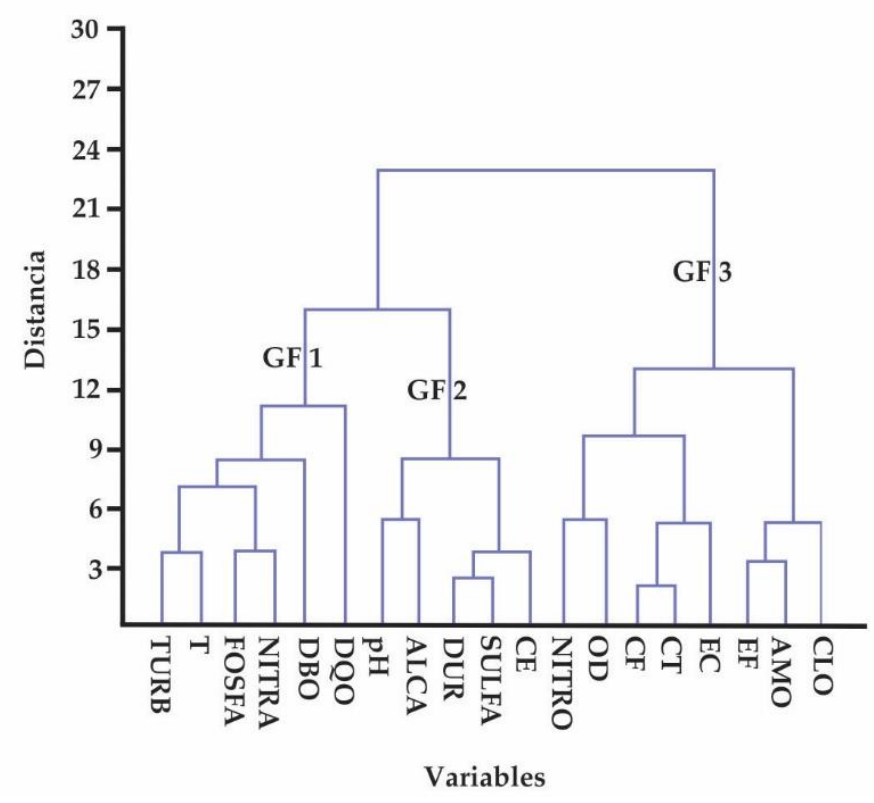

Figura 3. Dendrograma para las variables de la calidad del agua.

- GF 1: TURB, T, FOSFA, NITRA, DBO y DQO. Estas variables, en conjunto, están asociadas con la contaminación de origen agrícola, derivando los FOSFA y NITRA del común de fertilizantes usados por los agricultores de la región. La DQO y la DBO, sobre todo la primera, tienen una relación indirecta con los efluentes procedentes de la agricultura; sin embargo, están más íntimamente asociados con las aguas residuales domésticas (Shrestha \& Kazama, 2007).

En último lugar, es preciso volver a destacar la presencia de la TURB en este grupo, relacionada con la variación estacional propia del área de estudio, con veranos lluviosos que provocan cambios en la turbidez del agua del río. En relación con la TURB, este GF tiene cierta similitud con el CP 4 extraído del ACP, mientras que las variables DQO y DBO se corresponderían con el CP 2.

- GF 2: pH, ALCA, DUR, SULFA y CE. Estos parámetros físicos y químicos se encuentran relacionados con la geología básica propia del lugar; su análogo en el ACP sería el CP 3.

- GF 3: NITRO, OD, CF, CT, EC, EF, AMO y CLO. El origen de este grupo deriva de la contaminación antrópica, ya que el grupo de los coliformes se utiliza en la vigilancia de rutina como indicador de contaminación fecal en aguas (Percival, Yates, Williams, Chalmers, \& Gray, 2014). Además, las propiedades de los EF como indicadores de contaminación 
fecal, y la relación indirecta que el AMO y los CLO tienen con la misma, asocia estas variables con la contaminación antrópica. Por otra parte, AMO y CLO también tienen un estrecho vínculo con los fertilizantes agrícolas empleados a lo largo de la cuenca y su correspondiente escorrentía al cauce del río (Sundaray, Panda, Nayak, \& Bhatta, 2006).

El GF 3 presentó un nexo significativo con el CP 2 del ACP en cuanto al origen fecal de la contaminación del agua.

Estos grupos constituidos son semejantes a los formados como producto del análisis cluster en la cuenca del río Cértima (Portugal) (Figueiredo et al., 2012), en el cual la división de los mismos sigue dos principales situaciones: contaminación derivada de efluentes agrícolas, y contaminación derivada de efluentes animales y humanos.

\section{ACP de las estaciones de muestreo}

Se siguió la misma metodología antes empleada para el análisis de las variables, pero en este caso el objetivo fue evaluar la variación espacial a través del examen de las 43 estaciones de muestreo. En esta ocasión, el número de CP a partir del ACP (con valores propios superiores a 1) fue de ocho, entre los cuales sumaron $80.18 \%$ de la varianza (Tabla 3 ). De este modo se redujo el número de estaciones de muestreo de 43 a 10.

Tabla 3. Valores obtenidos del ACP para las estaciones de muestreo. Los valores en negrita corresponden a las estaciones de muestreo que contribuyen de forma significativa en cada CP.

\begin{tabular}{|l|c|c|c|c|c|c|c|c|}
\hline & CP 1 & CP 2 & CP 3 & CP 4 & CP 5 & CP 6 & CP 7 & CP 8 \\
\hline EM-01 & 0.145 & 0.101 & 0.238 & -0.122 & -0.040 & -0.177 & 0.297 & 0.068 \\
\hline EM-02 & 0.100 & 0.241 & 0.055 & -0.070 & -0.120 & -0.149 & -0.005 & 0.085 \\
\hline EM-03 & 0.111 & 0.194 & 0.279 & -0.087 & 0.037 & -0.089 & 0.272 & -0.013 \\
\hline EM-04 & 0.105 & 0.222 & 0.116 & -0.087 & -0.156 & -0.207 & 0.153 & 0.036 \\
\hline EM-05 & -0.085 & 0.046 & 0.074 & -0.058 & -0.074 & $-\mathbf{0 . 3 5 5}$ & -0.280 & 0.029 \\
\hline EM-06 & 0.057 & 0.181 & -0.058 & -0.065 & -0.023 & 0.048 & 0.158 & 0.230 \\
\hline EM-07 & -0.048 & -0.013 & 0.105 & -0.028 & -0.034 & 0.023 & -0.084 & 0.109 \\
\hline EM-08 & -0.046 & -0.076 & 0.073 & -0.002 & -0.038 & 0.063 & -0.043 & 0.076 \\
\hline EM-09 & 0.002 & 0.262 & 0.070 & -0.016 & 0.100 & 0.282 & 0.097 & -0.041 \\
\hline EM-10 & -0.185 & -0.155 & 0.031 & -0.112 & -0.001 & 0.047 & -0.163 & -0.103 \\
\hline
\end{tabular}


Ciencias Agua

\begin{tabular}{|c|c|c|c|c|c|c|c|c|}
\hline EM-11 & -0.096 & 0.110 & -0.002 & 0.185 & -0.141 & -0.180 & 0.025 & -0.019 \\
\hline EM-12 & -0.125 & -0.082 & 0.042 & 0.051 & -0.066 & -0.022 & -0.272 & 0.031 \\
\hline EM-13 & 0.019 & 0.131 & -0.172 & -0.038 & -0.064 & -0.109 & -0.110 & 0.162 \\
\hline EM-14 & -0.147 & -0.098 & 0.0996 & 0.045 & -0.075 & -0.010 & -0.039 & -0.039 \\
\hline EM-15 & -0.001 & -0.071 & 0.225 & -0.013 & 0.044 & 0.139 & -0.060 & -0.340 \\
\hline EM-16 & -0.070 & 0.073 & 0.169 & 0.038 & 0.076 & -0.003 & -0.419 & -0.037 \\
\hline EM-17 & 0.224 & -0.181 & 0.274 & 0.044 & -0.136 & -0.022 & -0.048 & -0.284 \\
\hline EM-18 & -0.105 & -0.046 & -0.039 & -0.196 & -0.023 & -0.064 & 0.089 & 0.087 \\
\hline EM-19 & -0.257 & -0.072 & 0.024 & -0.044 & -0.070 & -0.020 & 0.007 & 0.044 \\
\hline EM-20 & -0.157 & -0.111 & -0.258 & -0.077 & -0.234 & 0.003 & 0.235 & -0.326 \\
\hline EM-21 & -0.223 & -0.101 & -0.035 & -0.010 & 0.058 & 0.197 & 0.204 & 0.200 \\
\hline EM-22 & -0.077 & -0.080 & -0.056 & -0.028 & 0.044 & -0.122 & 0.163 & 0.059 \\
\hline EM-23 & -0.186 & -0.159 & 0.024 & 0.014 & 0.047 & -0.098 & -0.031 & 0.033 \\
\hline EM-24 & 0.140 & 0.050 & -0.169 & -0.763 & 0.220 & 0.166 & -0.199 & -0.087 \\
\hline EM-25 & -0.073 & -0.014 & 0.012 & -0.205 & 0.009 & -0.045 & -0.037 & 0.064 \\
\hline EM-26 & -0.158 & -0.012 & 0.055 & 0.032 & -0.134 & -0.027 & -0.101 & 0.056 \\
\hline EM-27 & 0.055 & 0.181 & 0.189 & 0.121 & 0.143 & & 0.030 & -0.064 \\
\hline EM-28 & -0.109 & -0.019 & 0.106 & 0.098 & -0.009 & 0.288 & 0.094 & 0.271 \\
\hline EM-29 & -0.165 & 0.024 & 0.052 & 0.104 & -0.141 & 0.007 & -0.080 & 0.015 \\
\hline EM-30 & -0.100 & 0.169 & 0.057 & 0.085 & 0.206 & 0.280 & 0.009 & 0.080 \\
\hline EM-31 & -0.159 & -0.229 & 0.030 & 0.033 & 0.099 & -0.006 & 0.164 & -0.009 \\
\hline EM-32 & 0.126 & -0.363 & 0.070 & 0.007 & -0.031 & 0.001 & 0.137 & 0.032 \\
\hline EM-33 & -0.042 & 0.010 & -0.077 & 0.068 & 0.342 & -0.245 & 0.143 & -0.418 \\
\hline EM-34 & 0.105 & -0.002 & -0.163 & 0.115 & 0.158 & -0.052 & 0.070 & -0.160 \\
\hline EM-35 & 0.062 & -0.188 & -0.205 & 0.100 & 0.178 & 0.021 & 0.186 & 0.132 \\
\hline EM-36 & -0.034 & 0.336 & -0.337 & 0.073 & -0.493 & 0.138 & 0.031 & -0.230 \\
\hline EM-37 & 0.225 & 0.064 & 0.046 & 0.118 & 0.240 & -0.222 & -0.036 & -0.039 \\
\hline EM-38 & 0.072 & -0.123 & -0.335 & 0.034 & 0.042 & 0.011 & 0.067 & -0.072 \\
\hline EM-39 & 0.114 & 0.021 & -0.280 & 0.097 & 0.034 & 0.160 & -0.186 & -0.028 \\
\hline EM-40 & 0.550 & -0.359 & 0.037 & -0.023 & -0.345 & 0.152 & -0.061 & 0.134 \\
\hline EM-41 & 0.183 & 0.082 & 0.023 & 0.283 & 0.077 & 0.193 & -0.130 & -0.156 \\
\hline EM-42 & 0.173 & 0.084 & -0.218 & 0.140 & 0.101 & -0.123 & -0.092 & 0.225 \\
\hline EM-43 & 0.083 & -0.026 & -0.171 & 0.161 & 0.198 & -0.175 & -0.144 & 0.211 \\
\hline
\end{tabular}

Los resultados mostraron que los $\mathrm{CP} 1,2,3$ y 5 agruparon estaciones de muestreo (EM-32, EM-33, EM-36, EM-38 y EM-40) situadas en el tramo bajo del río, y estuvieron afectados por excedentes agrícolas procedentes del cultivo de arroz, y por descargas domésticas 
procedentes de las localidades de Naranjos, Bagua Grande, Cajaruro y Bagua, principalmente. Para el CP 4, sólo la EM-24 obtuvo un valor por encima de 0.3; dicha estación se ubica en la quebrada El Chido, afluente por el margen derecho del río Utcubamba, y tiene la excepcionalidad de situarse aguas abajo de una granja de cerdos y otra de pollos, cuyos efluentes van de manera directa a la misma. El CP 8 (EM-15, EM-20 y EM-33) está compuesto por tres afluentes perturbados por la contaminación derivada del vertimiento de residuos sólidos, aguas arriba de las mismas, siendo el río Sonche (EM-20) el principal receptor de los mismos, que se generan en la ciudad de Chachapoyas. El CP 6 (EM-5 y EM-27) y CP 7 (EM-16) evidenciaron una relación con la transformación hidrogeomorfológica realizada en sus estaciones de muestreo a través de la instauración de canteras, que repercuten de forma negativa, sobre todo, en la calidad física del agua. A pesar de ello, estas tres estaciones se caracterizaron por poseer una contaminación moderada.

\section{AC de las estaciones de muestreo}

El AC expuso agrupaciones un tanto diferentes al ACP, resultando tres GF en la agrupación de estaciones de muestreo (Figura 4). La similitud con el ACP se dio, en su mayoría, en el tramo bajo del río, donde quedaron reunidas en el GF 3 (CP 1, 2, 3, 4 y 5 del ACP) las EM-32, $\mathrm{EM}-17$, EM-40, EM-39, EM-38, EM-35, EM-34, EM-43, EM-42, EM-41, EM-37, EM-33, EM-36 y EM-24. Si bien las estaciones 17 y 24 no pertenecen a este tramo de la cuenca, ellas, junto con el resto, presentaron características comunes de contaminación fecal, ya fuera de origen humano o animal. El dendrograma extraído del AC reflejó otros dos GF divididos en función de su nivel de contaminación, media o baja. Esta última división es la enfocada por Singh, Malik y Sinha (2005), quienes dividen la cuenca del río Gomti (India) en tres grupos, en función de la contaminación que presenten: alta, moderada y media. De esta manera, en el presente estudio, el GF 1 está formado por afluentes de pequeño caudal y sin grandes perturbaciones de origen antrópico. La contaminación se acentuó en el GF 2, constituido por estaciones de muestreo situadas en el cauce principal y en afluentes de importancia. Las estaciones situadas en la cuenca principal comienzan a aparecer aguas abajo de la primera localidad de consideración (Leymebamba), en la EM-5, que arroja sus residuos domésticos al propio río. Es destacable que EM situadas en el tramo medio, como la $25,26,28,29$ y 31 , que presumiblemente deberían 
tener una contaminación de origen fecal similar a las agrupadas en el GF 3, aparezcan en este GF 2. Sin embargo, la explicación está en que dicho tramo de la cuenca es el que posee más pendiente, con un relieve abrupto, denominado por Domenech, Ollero y Sánchez-Fabre (2008) como "curso fluvial con valle cerrado en cañón". Los saltos de agua existentes en este tramo oxigenan el agua (Gonzalo \& Camargo, 2013), y ayudan a descomponer la materia orgánica acumulada procedente de las granjas y poblaciones situadas aguas arriba.

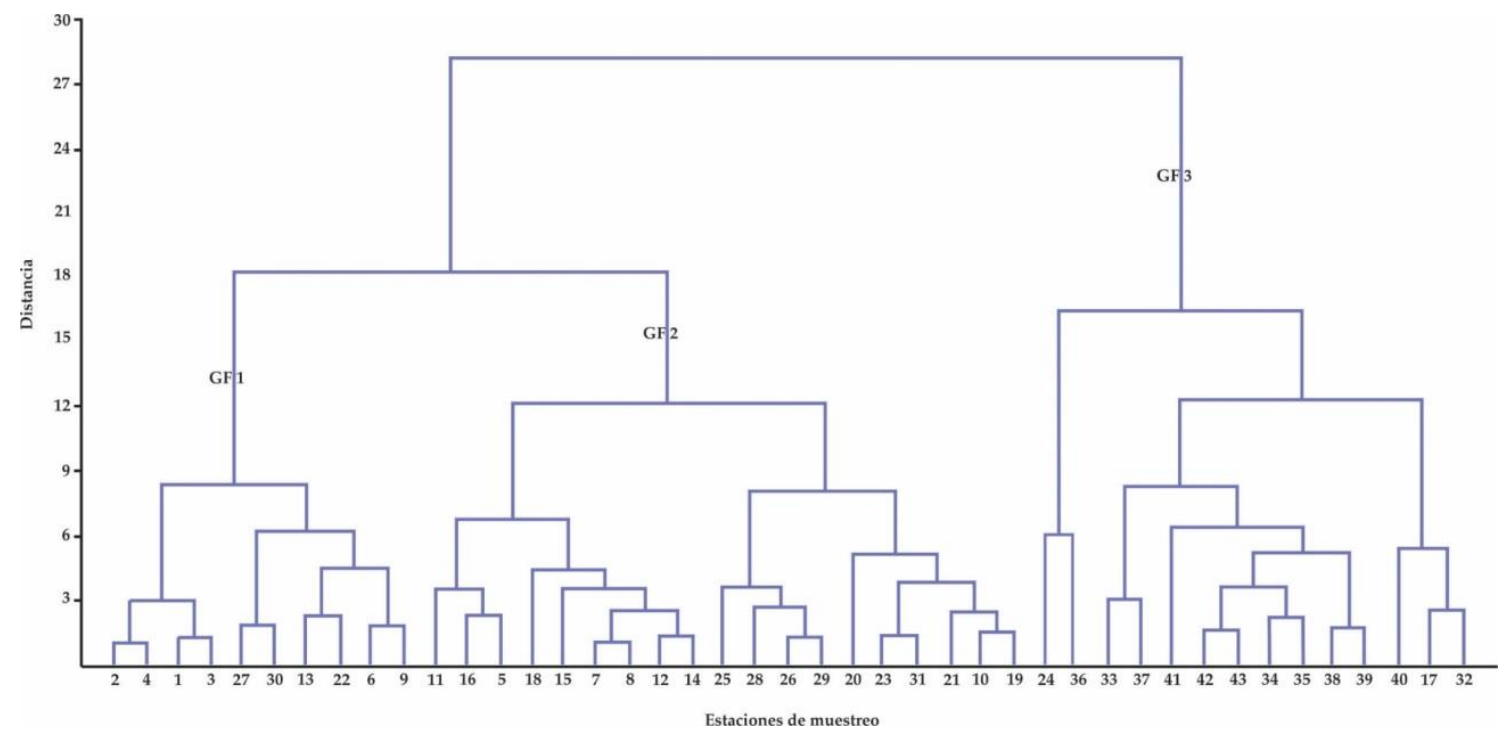

Figura 4. Dendrograma para las estaciones de muestreo.

\section{Conclusiones}

Los resultados obtenidos de la evaluación fisicoquímica y microbiológica del agua en la cuenca del río Utcubamba muestran un deterioro en su calidad debido a las descargas de aguas residuales de origen antrópico, agrícola y ganadero, teniendo en cuenta que no existe infraestructura de saneamiento municipal en toda la región. Existe una enorme carga contaminante por desechos fecales domésticos, sobre todo en el tramo bajo del río, con base en las altas concentraciones de bacterias indicadoras, como Escherichia coli y enterococos fecales, además de compuestos como nitritos, amonio y fosfatos obtenidos.

A través de métodos estadísticos multivariantes, como el $\mathrm{ACP}$, se dividió la cuenca en ocho CP con características similares. Asimismo, a 
través de un AC se dividió, de igual manera, la cuenca en tres GF: cada uno de ellos indicó un nivel distinto de contaminación.

Así, las técnicas estadísticas multivariantes empleadas sirvieron como excelente herramienta exploratoria en el análisis e interpretación de las variaciones temporales y espaciales presentes a lo largo de la cuenca del río Utcubamba, pues se consiguió reducir tanto el número de variables (de 19 a 13), como de estaciones de muestreo (de 43 a 10). Considerando que es el único estudio realizado en la cuenca del río Utcubamba, se podría reevaluar la situación cuando se lleven a cabo investigaciones posteriores en el corto plazo.

\section{Agradecimiento}

Al Programa Nacional de Innovación para la Competitividad y Productividad-FINCYT (Contrato $\mathrm{N}^{\circ}$ 221-FINCYT-IA-2013), por el apoyo brindado para la ejecución de esta investigación.

\section{Referencias}

Acosta, R., Ríos, B., Rieradevall, M., \& Prat, N. (2009). Propuesta de un protocolo de evaluación de la calidad ecológica de ríos altoandinos (CERA) y su aplicación a dos cuencas en Ecuador y Perú. Linmetica, 28(1), 35-64.

Álvarez-Cabria, M., Barquín, J., \& Peñas, F. J. (2016). Modelling the spatial and seasonal variability of water quality for entire river networks: Relationships with natural and anthropogenic factors. Science of the Total Environment, 545, 152-162. DOI: 10.1016/j.scitotenv.2015.12.109

Greenberg, A., Clesceri, L. S., \& Eaton, A.D. (1992). Standard methods for the examination of water and wastewater (18th ed). Washington, D.C., USA: American Public Health Association. Arcos-Pulido, M. P., Ávila-de-Navia, S. L., Estupiñán-Torres, S. M., \& Gómez-Prieto, A. C. (2005). Indicadores microbiológicos de contaminación de las fuentes de agua. Nova, 3(4), 69-79.

Arias, S. C., Pérez, J. C., \& Rueda, O. M. (2004). Lixiviación de nitratos en dos suelos al alterar sus propiedades físicas. Revista EIA, 2, 35-40. 
Arpajón, Y., Romeu, B., Rodríguez, A., Heydrich, M., Rojas, N., \& Lugo, D. (2011). Impacto de los nutrientes inorgánicos sobre la comunidad bacteriana del río Almendares (Cuba). Higiene y Sanidad Ambiental, 11, 731-738.

Azizullah, A., Nasir, A., Richter, P., Lebert, M., \& Häder, D. P. (2011). Evaluation of the adverse effects of two commonly used fertilizers, DAP and urea, on motility and orientation of the green flagellate Euglena gracilis. Environmental and Experimental Botany, 74, 140-150. DOI: 10.1016/j.envexpbot.2011.05.011

Calizaya-Anco, J., Avendaño-Cáceres, M., \& Delgado-Vargas, I. (2013). Evaluación de la calidad del agua fluvial con diatomeas (Bacillariophyceae), una experiencia en Tacna, Perú. Revista Peruana de Medicina Experimental y Salud Pública, 30(1), 58-63.

Carrera, P., \& Gunkel, G. (2003). Ecology of a high Andean stream, río Itambi, Otavalo, Ecuador. Limnológica, 33(1), 29-43. DOI:1016/S0075-9511(03)80005-1

Chamorro, S., Hernández, V., Matamoros, V., Domínguez, C., Becerra, J., Vidal, G., Piña, B., \& Bayona, J. M. (2013). Chemical characterization of organic microcontaminant sources and biological effects in riverine sediments impacted by urban sewage and pulp mill discharges. Chemosphere, 90(2), 611-619. DOI: $10.1016 /$ j.chemosphere.2012.08.053

Chávez, J., Leiva, D., \& Corroto, F. (2016). Caracterización fisicoquímica y microbiológica de las aguas residuales en la ciudad de Chachapoyas, Región Amazonas. Ciencia Amazónica, 6(1), 16-27. DOI: 10.22386/ca.v6i1.104

Chidya, R. C. G., Sajidu, S. M. I., Mwatseteza, J. F., \& Masamba, W. R. L. (2011). Evaluation and assessment of water quality in Likangala River and its catchment area. Physics and Chemistry of the Earth, 36(14), 865-871. DOI: 10.1016/j.pce.2011.07.070

Correa, S. W., Mello, C. R., Chou, S. C., Curi, N., \& Norton, L. D. (2016). Soil erosion risk associated with climate change at Mantaro River basin, Peruvian Andes. Catena, 147, 110-124. DOI: $10.1016 /$ j.catena.2016.07.003

Crespo, P. J., Feyen, J., Buytaert, W., Bücker, A., Breuer, L., Frede, H. G., \& Ramírez, M. (2011). Identifying controls of the rainfallrunoff response of small catchments in the tropical Andes (Ecuador). Journal of Hydrology, 407(1), 164-174. DOI: 10.1016/j.jhydrol.2011.07.021

Digesa, Dirección General de Salud Ambiental. (2007). Protocolo de monitoreo de la calidad sanitaria de los recursos hídricos superficiales. Dirección General de Salud Ambiental. Recovered 
from

http://www.digesa.minsa.gob.pe/depa/informes_tecnicos/PROT OCOLO-MONITOREO-CALIDAD-RECURSOS-HIDRICOSSUPERFICIALES-(CONTINENTALES).pdf

Domenech, S. Ollero, A., \& Sánchez-Fabre, M. (2008). Núcleos de población en riesgo de inundación fluvial en Aragón: diagnóstico y evaluación para la ordenación del territorio. Geographicalia, 54, 17-44.

Dos Santos, J. S., De Oliveira, E., Bruns, R. E., \& Gennari, R. F. (2004). Evaluation of the salt accumulation process during inundation in water resource of Contas river basin (Bahia-Brazil) applying principal component analysis. Water Research, 38(6), 1579-1585. DOI: 10.1016/j.watres.2003.12.006

Figueiredo, D. R., Ferreira, R. V., Cerqueira, M., De Melo, T. C., Pereira, M. J., Castro, B. B., \& Correia, A. (2012). Impact of water quality on bacterioplankton assemblage along Cértima River Basin (central western Portugal) assessed by PCR-DGGE and multivariate analysis. Environmental monitoring and assessment, 184(1), 471-485. DOI: 10.1007/s10661-011-19812

Gemmell, M. E., \& Schmidt, S. (2012). Microbiological assessment of river water used for the irrigation of fresh produce in a suburban community in Sobantu, South Africa. Food Research International, 47(2), 300-305,

DOI: 10.1016/j.foodres.2011.07.016

Gonzalo, C., \& Camargo, J. A. (2013). The impact of an industrial effluent on the water quality, submersed macrophytes and benthic macroinvertebrates in a dammed river of Central Spain. Chemosphere, 93(6), 10.1016/j.chemosphere.2013.06.032

Hair, J. F., Anderson, R. E., Tatham, R. L., \& Black, W. C. (1999). Análisis multivariante ( $5^{\mathrm{a}}$ ed.). Madrid, España: Prentince Hall.

Hamilton, S. K., Kellndorfer, J., Lehner, B., \& Tobler, M. (2007). Remote sensing of floodplain geomorphology as a surrogate for biodiversity in a tropical river system (Madre de Dios, Peru). Geomorphology, 89(1), 23-38.

DOI: 10.1016/j.geomorph.2006.07.024

Hammer, Ø., Harper, D. A. T., \& Ryan, P. D. (2001). Paleontological statistics software package for education and data analysis. Palaeontologia Electronica, 4(1), 1-9.

INEI, Instituto Nacional de Estadística e Informática (2009). Estimaciones y proyecciones de población por sexo, según 
departamento, provincia y distrito, 2000-2015, 18. Recovered from

http://proyectos.inei.gob.pe/web/biblioineipub/bancopub/Est/Lib 0842/libro.pdf

Jacobsen, D. (2004). Contrasting patterns in local and zonal family richness of stream invertebrates along an Andean altitudinal gradient. Freshwater Biology, 49(10), 1293-1305. DOI: 10.1111/j.1365-2427.2004.01274.x

Kaiser, H. F. (1958). The varimax criterion for analytic rotation in factor analysis. Psychometrica, 23(3), 187-200. DOI: 10.1007/BF02289233

León, B., Pitman, N., \& Roque, J. (2006). Introducción a las plantas endémicas del Perú. Revista peruana de biología, 13(2), 9-22.

Linares-Palomino, R. (2004). Los bosques tropicales estacionalmente secos: I. El concepto de los bosques secos en el Perú. Arnaldoa, 11(1), 85-102.

Martínez-García, G., Johnson, A. C., Bachmann, R. T., Williams, C. J., Burgoyne, A., \& Edyvean, R. G. (2009). Anaerobic treatment of olive mill wastewater and piggery effluents fermented with Candida tropicalis. Journal of Hazardous Materials, 164(2), 13981405. DOI: $10.1016 / j$.jhazmat.2008.09.055

Olsen, R. L., Chappell, R. W., \& Loftis, J. C. (2012). Water quality sample collection, data treatment and results presentation for principal components analysis-literature review and Illinois River watershed case study. Water Research, 46(9), 3110-3122. DOI: 10.1016/j.watres.2012.03.028

Pardo, C. E., \& Del Campo, P. C. (2007). Combinación de métodos factoriales y de análisis de conglomerados en $\mathrm{R}$ : el paquete FactoClass. Revista Colombiana de Estadística, 30, 231-245.

Percival, S. L., Yates, M. V., Williams, D., Chalmers, R., \& Gray, N.. (2014). Microbiology of waterborne diseases: Microbiological aspects and risks ( $2^{\mathrm{a}} \mathrm{Ed}$.). London UK: Academic Press.

Perú-IIAP, Instituto de Investigaciones de la Amazonía Peruana, Iquitos (2008). Zonificación ecológica y económica del Departamento de Amazonas. Recuperado de http://www.iiap.org.pe/upload/publicacion/PUBL520.pdf

Picado, A., Mendonça, E., Silva, L., Paixão, S. M., Brito, F., Cunha, M. A., Leitão, S., Moura, I., \& Hernan, R. (2008). Ecotoxicological assessment of industrial wastewaters in Trancão River Basin (Portugal). Environmental Toxicology, 23(4), 466-472. DOI: 10.1002/tox.20359 
Prat, N., Rieradevall, M., \& Fortuño, P. (2012) Metodología F.E.M. para la evaluación del estado ecológico de los ríos mediterráneos. Barcelona, España: Universidad de Barcelona. Recovered from http://www.ub.edu/fem/docs/protocols/fem_\%20prot_cast_201 2.pdf

Prescott, L., Harley, J., \& Klein, D. (1996). Microbiología (5 ${ }^{\text {a ed.). }}$ Madrid, España: Ed. McGraw-Hill.

Rossignol, K. L., Paerl, H. W., Fear, J. M., \& Braddy, J. S. (2011). Nutrients in precipitation and the phytoplankton responses to enrichment in surface waters of the Albemarle Peninsula, NC, USA after the establishment of a large-scale chicken egg farm. Hydrobiologia, 671(1), 181-191. DOI: 10.1007/s10750011-0715-3

Schulz, C., Gelbrecht, J., \& Rennert, B. (2003). Treatment of rainbow trout farm effluents in constructed wetland with emergent plants and subsurface horizontal water flow. Aquaculture, 217(1), 207221.

Segnini, S., \& Chacón, M. M. (2005). Caracterización fisicoquímica del hábitat interno y ribereño de los ríos andinos en la cordillera de Mérida, Venezuela. Ecotrópicos, 18(1), 38-61.

Shrestha, S., \& Kazama, F. (2007). Assessment of surface water quality using multivariate statistical techniques: A case study of the Fuji river basin, Japan. Environmental Modelling \& Software, 22(4), 464-475. DOI: 10.1016/j.envsoft.2006.02.001

Singh, K. P., Malik, A., Mohan, D., \& Sinha, S. (2004). Multivariate statistical techniques for the evaluation of spatial and temporal variations in water quality of Gomti River (India). A case study. Water research, 38(18), 3980-3992, doi: 10.1016/j.watres.2004.06.011

Singh, K. P., Malik, A., \& Sinha, S. (2005). Water quality assessment and apportionment of pollution sources of Gomti river (India) using multivariate statistical techniques. A case study. Analytica Chimica Acta, 538(1-2), 355-374. DOI: 10.1016/j.aca.2005.02.006

Solaraj, G., Dhanakumar, S., Murthy, K. R., \& Mohanraj, R. (2010). Water quality in select regions of Cauvery Delta River basin, southern India, with emphasis on monsoonal variation. Environmental Monitoring and Assessment, 166(1-4), 435-444. DOI: $10.1007 /$ s10661-009-1013-7

Struth, L., Babault, J., \& Teixell, A. (2015). Drainage reorganization during mountain building in the river system of the Eastern 
Cordillera of the Colombian Andes. Geomorphology, 250, 370383. DOI: $10.1016 /$ j.geomorph.2015.09.012

Sunantha, G., \& Vasudevan, N. (2016). Assessment of bacterial indicators and physico-chemical parameters in Tiruppur, Erode and Chennai, Tamil Nadu (India). Environmental Nanotechnology, Monitoring \& Management, 6, 219-260. DOI: 10.1016/j.enmm.2016.10.005

Sundaray, S. K., Panda, U. C., Nayak, B. B., \& Bhatta, D. (2006). Multivariate statistical techniques for the evaluation of spatial and temporal variations in water quality of the Mahanadi riverestuarine system (India). A case study. Environmental Geochemistry and Health, 28(4), 317-330. DOI: 10.1007/s10653-005-9001-5

Tanaka, A., Diagne, M., \& Saito, K. (2015). Causes of yield stagnation in irrigated lowland rice systems in the Senegal River Valley: Application of dichotomous decision tree analysis. Field Crops Research, 176, 99-107. DOI: 10.1016/j.fcr.2015.02.020

Terradez, G. M. (2002). Análisis de componentes principales. Proyecto e-Math. Recuperado de https://es.calameo.com/read/000191970a476fb6ab58c

Tshibanda, J. B., Devarajan, N., Birane, N., Mwanamoki, P. M., Atibu, E. K., Mpiana, P. T., Prabakar, K., Ilunga, J. M., Wildi, W., \& Poté, J. (2014). Microbiological and physicochemical characterization of water and sediment of an urban river: N'Djili River, Kinshasa, Democratic Republic of the Congo. Sustainability of Water Quality and Ecology, 3-4, 47-54. DOI: $10.1016 /$ j.swaqe.2014.07.001

USEPA, United States Environmental Protection Agency. (2000). Improved Enumeration Methods for the Recreational Water Quality Indicators: Enterococci and Escherichia coli EPA-821/R97/004. Washington, DC: U.S. Environmental Protection Agency.

Vega, M., Pardo, R., Barrado, E., \& Debán, L. (1998). Assessment of seasonal and polluting effects on the quality of river water by exploratory data analysis. Water Research, 32(12), 3581-3592. DOI: $10.1016 / S 0043-1354(98) 00138-9$

Velázquez-Machuca, M. A., Pimentel-Equihua, J. L., \& Ortega-Escobar, M. (2010). Variaciones longitudinales y temporales en la hidroquímica del río Duero. Agrociencia, 44(5), 599-609.

Vieira, J. S., Pires, J. C., Martins, F. G., Vilar, V. J., Boaventura, R. A., \& Botelho, C. M. (2012). Surface water quality assessment of Lis River using multivariate statistical methods. Water, Air, \& Soil 
Pollution, 223(9), 5549-5561. DOI: 10.1007/s11270-012-12675

Villamarín, C., Prat, N., \& Rieradevall, M. (2014). Caracterización física, química e hidromorfológica de los ríos altoandinos tropicales de Ecuador y Perú. Latin American Journal of Aquatic Research, 42(5), 1072-1086. DOI: 10.3856/vol42-issue5fulltext-12

Villegas, P., Paredes, V., Betancur, T., \& Ribeiro, L. (2013). Assessing the hydrochemistry of the Urabá Aquifer, Colombia by principal component analysis. Journal of Geochemical Exploration, 134, 120-129. DOI: 10.1016/j.gexplo.2013.08.011

Wang, Y., Wang, P., Bai, Y., Tian, Z., Li, J., Shao, X., Mustavich, L. F., \& Li, B. L. (2013). Assessment of surface water quality via multivariate statistical techniques: A case study of the Songhua River Harbin region, China. Journal of Hydro-Environment Research, 7(1), 30-40. DOI: 10.1016/j.jher.2012.10.003

Wopereis-Pura, M. M., Watanabe, H., Moreira, J., \& Wopereis, M. C. S. (2002). Effect of late nitrogen application on rice yield, grain quality and profitability in the Senegal River valley. European Journal of Agronomy, 17(3), 191-198.

Xu, J., Zhao, Y., Zhao, G., \& Zhang, H. (2015). Nutrient removal and biogas upgrading by integrating freshwater algae cultivation with piggery anaerobic digestate liquid treatment. Applied Microbiology \& Biotechnology, 99(15), 6493-6501. DOI: 10.1007/s00253-015-6537-x

Zhang, Z., Gao, J., Fan, X., Lan, Y., \& Zhao, M. (2017). Response of ecosystem services to socioeconomic development in the Yangtze River Basin, China. Ecological Indicators, 72, 481-493. DOI: $10.1016 /$ j.ecolind.2016.08.035

Zou J., Lu, J. W., Li, Y. S., \& Li, X. K. (2011). Regional evaluation of winter rapeseed response to $\mathrm{K}$ fertilization, $\mathrm{K}$ use efficiency, and critical level of soil $\mathrm{K}$ in the Yangtze River Valley. Agricultural Sciences in China, 10(6), 911-920. 